\title{
专访催化领域代表人物——张铁锐研究员
}

\author{
《物理化学学报》编辑部
}

北京大学化学与分子工程学院, 北京 100871

\section{Interview with the Leader of Catalysis: Prof. Tierui Zhang}

\author{
Editorial Office of Acta Physico-Chimica Sinica \\ College of Chemistry and Molecular Engineering, Peking University, Beijing 100871, China. \\ Email: whxb@pku.edu.cn \\ Published online: October 21, 2020.
}

催化领域涉及反应分子在催化材料作用下的一系列物理化学过程, 是材料科学与界面科学的重要交 叉。百余年来, 催化领域的发展对人类的生产生活产生了重大的推动作用, 并相继诞生了热催化、电催 化、光催化等重要分支学科。当今该领域的研究热点主要分为两个方面, 分别是偏向基础研究的催化材 料界面局部电荷转移与能量传递过程, 以及偏向应用研究的催化体系工程设计, 呈现出由微观到宏观、 由基础到应用的全面发展态势。本期我们有幸采访了国内催化领域的代表人物, 《物理化学学报》编委 张铁锐研究员, 为我们分享了他的研究经历及对国内外催化行业的分析。

问题 1：请您为读者们简单介绍一下您的科研历 程。

回答: 我于1994年入学我的母校吉林大学化学系, 开始我的化学学习之路, 并于1998年取得理学学 士学位, 于2003年取得吉林大学有机化学博士学 位。同年, 我进入德国马普胶体界面研究所胶体 系, 跟从Prof. Markus Antonietti和Prof. Charl F. J. Faul研究组研究杂多金属氧酸盐的组装及其光电 性能。2004年10月加入加拿大国家纳米研究所\&阿 尔伯塔大学化学系Prof. Hicham Fenniri研究组, 从 事具有SERS活性的条形码树脂的制备及其作为 传感器的研究。2005年8月出站后进入美国阿肯色 大学化学与生物化学系Prof. Z. Ryan Tian研究组, 从 事氧化锌和二氧化钛纳米材料及光催化应用的研 究, 并于2007年1月出站。之后于2007年2月进入美 国加州大学河滨分校化学系和化工系Prof. Yadong Yin和Prof. Yushan Yan研究组, 从事介孔空心纳米 材料的制备及催化应用研究, 于2009年10月出站。 同年11月, 我回国进入中国科学院理化技术研究 所, 中国科学院光化学转换与功能材料重点实验 室, 以研究员、中科院特聘研究员、博士生导师的
角色从事能源纳米催化材料研究至今。

问题2：是什么把您吸引到催化的研究领域的呢？在 科研的道路上有哪些重要的人影响了您?

回答：我认为催化领域之所以吸引了诸多学者的 原因在于其背后蕴含着改变世界的可能性。合理 的利用一个催化反应可以拯救数以万计的生命, 例如合成氨反应解决了世界粮食危机问题。而若 是不正当地利用了催化的金钥匙又会致使数万人 陷入战乱, 流离失所, 像是纳粹德国利用费托合成 反应发动战争。我们虽生于和平年代, 吃饱穿暖, 但我们面临的问题, 如能源危机、全球变暖等问题 却一点不比当年缓和。而我认为这些艰难险阻的 “七寸”正是一个一个的催化反应。试想, 自己在实 验室里的一个小小的杜杆可能尧起一次全人类的 进步, 这难道不让人着迷吗? 而提到给我影响最 大的人, 我首先想到的便是光催化之父, 来自日本 的藤岛昭先生, 他在实验室无意发现半导体二氧 化钛具有明显的光电效应并将其用在光驱动分解 水产氢产氧以及杀菌降解等领域。至此, 光催化的 大门正式被打开, 就像普罗米修斯之火一般, 在创 
造了新的领域的同时也点燃了诸多传统领域。而 同时被点燃的, 还有包括我在内的分布在全球的 科研工作者们的激情。

问题3: 中国催化的研究在国际上处于什么位置?

回答: 中国催化的研究水平目前无疑是处于世界 前列的。无论是从文章的发表量, 从事研究的人员 数量以及投入的经费等数据来看都是数一数二 的。我们当然可以以此为豪, 但我认为我们也需要 保持一定的危机感, 时常修正研究领域的主干线, 因为我们的研究不光要广, 要大, 还要优, 要深, 要有用。

问题4: 目前催化领域的发展存在的最大的挑战有 哪些?未来有哪些发展趋势?

回答: 我认为目前催化领域处于一个多点开花的 状态。新的反应、新的体系、旧的反应和新的体系 结合等等, 每天都会报道出一些新奇的想法。但似 乎对于科学问题的深度以及实际应用问题的精度 的研究相对较少。科学是用来指导实践的, 而催化 更是如此。从事催化领域研究的人肯定都清楚, 这 是一个十分艰巨的挑战。实验室再完美也只能模 拟实际的应用, 科研到应用的转化必须建立在对 实验本身研究足够深, 对可能产生的应用问题的 分析足够细的基础上。这便是目前面临的最大挑 战。而发展趋势一直以来都是与挑战伴生的, 明确 了挑战也就明确了发展趋势。我认为, 未来催化领 域的发展应保持在探索新领域的同时, 加强对科 学深度的钻研并积极地尝试科研成果转化。

问题5: 请您列举一些您课题组现阶段主要的研究方 向和学术成果。

回答: 我目前主要针对光催化合成太阳能燃料及 高附加值化学品开展相关研究工作。近年来一些 高效非贵金属光催化剂, 特别是水滑石基光催化 材料的发现极大地激发了我们对于这一科学领域 的研究兴趣。众所周知, 水滑石是一种由带正电荷 的主体层板和层间阴离子通过非共价键相互作用 形成的二维晶体材料。它具有主体层板化学组成 可调控, 层间阴离子电荷和数量可调节等突出特 点。近年来, 我们利用水滑石基光/电纳米催化材 料, 从构建高效的表界面活性位这一角度出发, 主 要在以下三个方面开展了相关工作：1)通过可控 合成水滑石超薄纳米结构研究表面缺陷对反应分 子的吸附与活化; 2)通过构筑水滑石基催化材料
界面结构调控中间物种反应路径; 3)采用介孔 $\mathrm{SiO}_{2}$ 封装策略强化活性位, 保证催化剂稳定运行并富 集反应分子。未来, 我们还将在原子尺度、纳米尺 度及介观尺度等多尺度构建及调控包括水滑石基 催化材料在内的非贵金属光催化材料的表界面活 性位, 以期待进一步提升太阳能燃料及高附加值 化学品催化合成中的活性及选择性。同时, 我们也 将致力于发展更多高效的非贵金属光催化剂, 并 利用多能量耦合如光热协同催化、光电协同催化 等手段进一步拓宽其应用价值, 在基础研究成果 产业化方面作初步尝试。

问题6: 您认为催化发展和应用对我们的社会、环 境和经济会有哪些影响?

回答: 正如我前面提到的, 催化反应蕴含着改变人 类命运的可能性。我在这里可以大胆的猜想, 依赖 不可再生能源的传统的催化工艺完全被新型、清 洁、可再生能源所替代后, 以争夺不可再生资源而 引发的战争将彻底消失; 没有了污染, 全球的自然 生态环境质量大大提高, 各类以化工品为原料生 产的商品成本将大大降低, 更多的精力和资源被 节约出来从而可能促成诸多新技术、新领域的迅 猛发展, 最终真正实现自然和人类文明的全面和 谐相处。

问题7: 在您的科研生涯中, 有什么印象深刻的事 情与读者们分享吗?

回答: 最让我印象深刻的无疑是我在美国做博士 后研究期间, 在一次合成实验的过程中, 我误将一 个药品的用量多加了十倍。原以为是一次彻底失 败的实验, 但在后续的仔细观察中却发现了十分 有趣的现象, 据此现象展开了后续的研究, 最终得 到了欣喜的结果, 并发表于德国应用化学期刊上, 这也是我个人的第一篇德国应用化学。这样有趣 的过程也时刻提醒我, 建立在安全的前提下, 实验 永远不要怕失败, 只要有仔细的观察, 每一次实验 都是有价值的。

问题8: 您认为科研人员最重要的品质是什么? 您对 研究生或年轻的科研工作者有什么建议?

回答: 我认为对于一个科研人员来说, 最重要的品 质就是坚韧。科研从来都不会是容易的, 这是它本 身的价值赋予它的特征。最有价值的科研成果一 定是靠咬定青山不放松的拼搏得到的。尤其是对 于年轻的科研工作者而言, 年轻赋予了你们更多 
的活力, 同时也给了你们更多的考验。大千世界, 花花万物都充分刺激着你们的身心, 而身为一名 科研工作者则要专心科学, 要坚信科学带给你们 的享受绝不比其他任何事物的差。而在科研之余, 也要适当的开拓视野, 丰富自己的生活, 热爱科研 却不被科研绑架, 以一个健康向上的姿态去迎接 年轻和科学二词带给你们的使命。

问题9: 工作之余, 您有什么兴趣爱好?

回答: 我最大的爱好是化学主题方面的集邮。我从 小就喜欢收集邮票, 这个爱好大约8岁的时候就开 始了, 一直到大学。因为我学的专业是化学, 从事 科研工作以来, 我越来越关注化学主题方面的集 邮, 包括化学家头像邮册、诺贝尔化学奖获奖主题 邮册等等。集邮带给我的快乐不仅在于收集、寻找 的过程, 我认为邮票既是历史记忆的载体, 方寸之 间又包罗万象。通过集邮, 它激发了我对所在学科 的兴趣以及发展脉络的了解, 让我感受到科学的
魅力所在。我认为出色的科学研究和优雅的艺术 创作是不分家的。邮票中化繁为简, 精益求精的美 学思想和我所追求的科研态度也不谋而合。

问题 10: 请问您认为什么是期刊发展最重要的因 素?

回答: 结合当下情况, 我认为一个期刊发展的最重 要的因素就是严谨。期刊是全球科研工作的展示 平台也是交流平台。我对于近年来发生的诸多撤 稿事件, 深表遗憾和愤慨, 学术不端行为对于科研 的发展尤其是一些交叉学科的研究往往是致命 的。抵制学术不端行为需要科研工作者们和期刊 工作者们携手完成, 科研工作者需要警钟长鸣, 牢 牢守住红线, 把好第一关, 而优秀的期刊也应完善 和优化审阅机制, 守住抵制学术不端的第二道关 卡。只有这样才能给予科研健康的土壤, 开出真正 绚丽的花朵。

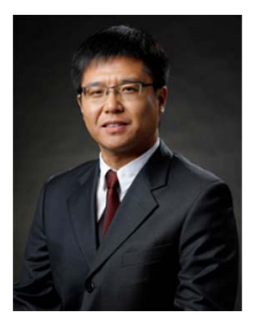

张铁锐, 中国科学院理化技术研究所研究员、博士生导师, 中国科学院光化学转化 与功能材料重点实验室主任。吉林大学化学学士(1994-1998), 吉林大学有机化学博士 (1998-2003)。之后，在德国(2003-2004)、加拿大(2004-2005)和美国(2005-2009)进行博 士后研究。2009年底回国受聘于中国科学院理化技术研究所。主要从事能量转换纳米催 化材料方面的研究, 在Nat.Commun., Adv. Mater., Angew.Chem.Int.Ed., JACS, Chem. Soc. Rev.等期刊上发表SCI论文200余篇, 被引用 17000 多次, H指数 70, 并入选2018、2019、 2020 科睿唯安 “全球高被引科学家”; 申请国家发明专利42项(已授权31项), 在国际会议上做特邀报告 40 余次。2017年当选英国皇家化学会会士。曾获得：皇家学会高级牛顿学者、德国 “洪堡” 学者基金、国 家基金委 “杰青”、国家 “万人计划” 科技创新领军人才等资助、以及太阳能光化学与光催化领域优秀 青年奖等奖项。兼任Science Bulletin副主编以及Advanced Energy Materials、Advanced Science、Scientific Reports、Materials Chemistry Frontiers、ChemPhysChem、SolarRRL、Carbon Energy、Innovation、SmartMat、 Acta Physico-Chimica Sinica等期刊编委。现任中国材料研究学会青年工作委员会-常委, 中国感光学会光 催化专业委员会-副主任委员、中国化学会青年工作者委员会-委员等学术职务。 